\title{
Artificial intelligence and capsule endoscopy: unravelling the future
}

\author{
Miguel Mascarenhas, João Afonso, Patrícia Andrade, Hélder Cardoso, Guilherme Macedo \\ Hospital de São João, Porto, Portugal
}

\begin{abstract}
The applicability of artificial intelligence (AI) in gastroenterology is a hot topic because of its disruptive nature. Capsule endoscopy plays an important role in several areas of digestive pathology, namely in the investigation of obscure hemorrhagic lesions and the management of inflammatory bowel disease. Therefore, there is growing interest in the use of AI in capsule endoscopy. Several studies have demonstrated the enormous potential of using convolutional neural networks in various areas of capsule endoscopy. The exponential development of the usefulness of AI in capsule endoscopy requires consideration of its medium- and long-term impact on clinical practice. Indeed, the advent of deep learning in the field of capsule endoscopy, with its evolutionary character, could lead to a paradigm shift in clinical activity in this setting. In this review, we aim to illustrate the state of the art of AI in the field of capsule endoscopy.
\end{abstract}

Keywords Capsule endoscopy, artificial intelligence, deep learning, machine learning, gastroenterology

Ann Gastroenterol 2021; 34 (2): 1-10

\section{Introduction}

Artificial intelligence (AI) has played an increasing role in the technological development of clinical practice and biomedical academic activity [1]. The potential of AI has applications over a range of different medical specialties, while specialties with a strong imaging and diagnostic component have assumed a leading position in the implementation of this technology [2]. Indeed, there is a growing awareness and perception of the innumerable opportunities and disruptive nature of $\mathrm{AI}$ in clinical practice [3].

$\mathrm{AI}$ is defined as the use of computers and technology to simulate intelligent behavior and critical thinking comparable to that of a human being [4]. The ever growing need to provide high-quality and cost-efficient global healthcare has resulted in a corresponding expansion in the development of computerbased and robotic healthcare tools that rely on artificially intelligent technologies [5]. In 2016, healthcare was the most funded sector regarding AI research, and investment continues

Gastroenterology Department, Hospital de São João, Porto, Portugal

Conflict of Interest: None

Correspondence to: Miguel Mascarenhas, Gastroenterology Department, Hospital de São João, 4200-427 Porto, Portugal, e-mail: miguelmascarenhassaraiva@gmail.com

Received 26 October 2020; accepted 20 December 2020; published online 26 February 2021

DOI: https://doi.org/10.20524/aog.2021.0606 to pour into this sector [6]. AI, machine learning (ML), and deep learning are overlapping disciplines [7], with many current applications in the various fields of the healthcare sector. With the advent of the big data era, the accumulation of a gigantic number of digital images and medical records created an unparalleled set of resources for ML [8]. The relationship between AI, ML, and deep learning is summarized in Fig. 1.

ML is based on the recognition of patterns that can be applied to medical images [9], laboratory medicine [10], drug discovery [11], and even clinical practice [12]. ML is based on the introduction of algorithms that ingest input data, apply computer analysis to predict output values within an acceptable range of accuracy, identify patterns and trends within the data, and finally learn from previous experience [13]. ML can be either supervised or unsupervised.

A supervised ML algorithm uses the available training data (images from capsule endoscopy for example) to learn a function by mapping certain input variables/features from the training data onto a qualitative or quantitative output/target (e.g., identifying protuberant lesions in the small bowel) [14]. A frequently used example is training a model to differentiate between apples, oranges and lemons. The "label" of each type of fruit is supplied to the algorithm, along with features such as color, size, weight and shape, and by referring to a set of learning data the algorithm determines the combinations of features that differentiate the fruits [15]. In medical applications, once a model has been developed and perfected, it is tested on novel patients whose data were not included in the training set, to determine its external validity and subsequent applicability to other patients [13].

On the other hand, unsupervised ML methods rely on the arbitrary aggregation of unlabeled data sets to yield groups 
or clusters of entities with shared similarities that may be unknown to the user prior to the analysis [14]. Unsupervised ML algorithms are data-driven techniques that automatically learn from the relationships between elementary bits of information associated with each variable of a dataset [16]. The combination of and potential synergy between supervised and unsupervised methods of ML holds great promise in the field of gastroenterological endoscopy.

Deep learning is a subset of ML. The structure of neural networks, organized in multiple layers, allows them to address complex tasks [17]. Deep neural networks use the compositional hierarchy of signals, in which higher-level features are obtained by combining lower-level ones [18]. A convolutional neural network (CNN, or ConvNet) is a class of deep neural networks tailored to visualimageryanalysis. CNNsresembleneurobiological processes, emulating the connectivity pattern between neurons [19]. In Fig. 2 we can see the similarities between a human neural

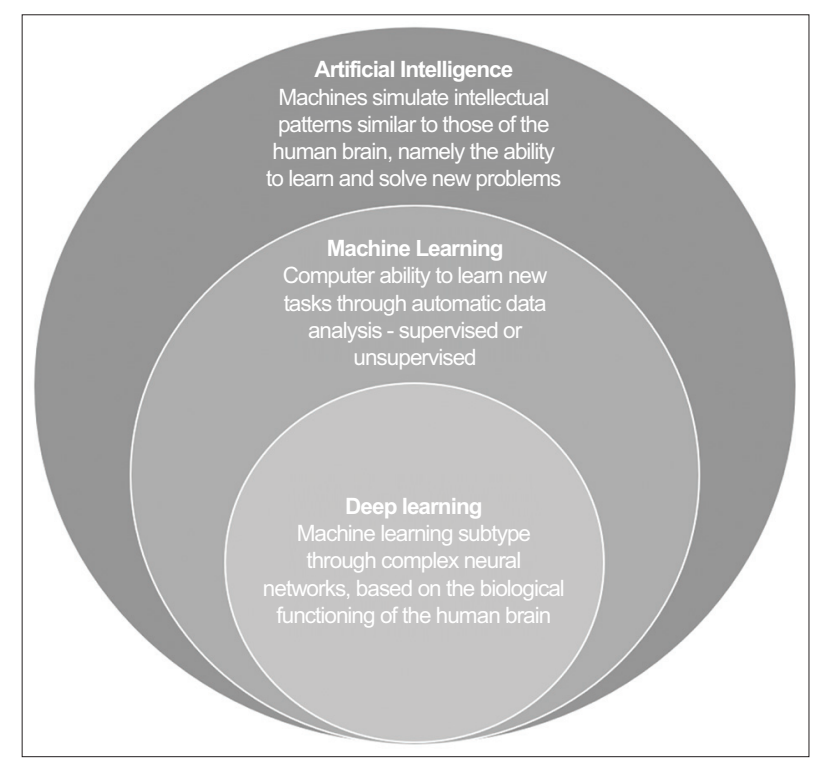

Figure 1 Relationship between different levels of artificial intelligence network and a deep learning algorithm. CNNs are a type of feedforward artificial neural network inspired by the organization of the animal visual cortex, whose individual neurons are arranged in such a way that they respond to overlapping regions tiling the visual field [20]. Therefore, CNNs require less preprocessing and are also less dependent on prior knowledge and human effort. CNNs exhibit superior performance when compared to other deep learning architectures, namely in terms of object detection and recognition [21]. The fields of application of CNNs vary from abnormality detection and disease classification to computeraided diagnosis [22]. Deep learning and CNNs are disruptive and have excelled in the detection of a range of diseases in capsule endoscopy [23].

\section{Application in capsule endoscopy}

Capsule endoscopy is one of the branches of gastroenterology that can benefit the most from the application of this type of technology. Indeed, the use of AI in this field shows great promise and capsule endoscopy can serve as a stepping stone for the broader application of AI in endoscopy and gastroenterology. Below, we summarize the state of the art regarding the use of $\mathrm{AI}$ in capsule endoscopy.

\section{Al and bleeding lesions}

One of the fields in which the automation of videocapsule diagnostics has undergone enormous advances is in the detection of gastrointestinal (GI) hemorrhage, namely from ulcers and vascular lesions. In 2007, Lau et al developed a model capable of detecting the presence of hemorrhage with a sensitivity of $88.3 \%$, using simple color coding. However, this model was limited by the very low quality of the analyzed video images [24]. In the following year, Giritharan et al analyzed 400 frames of GI hemorrhage using a support-vector

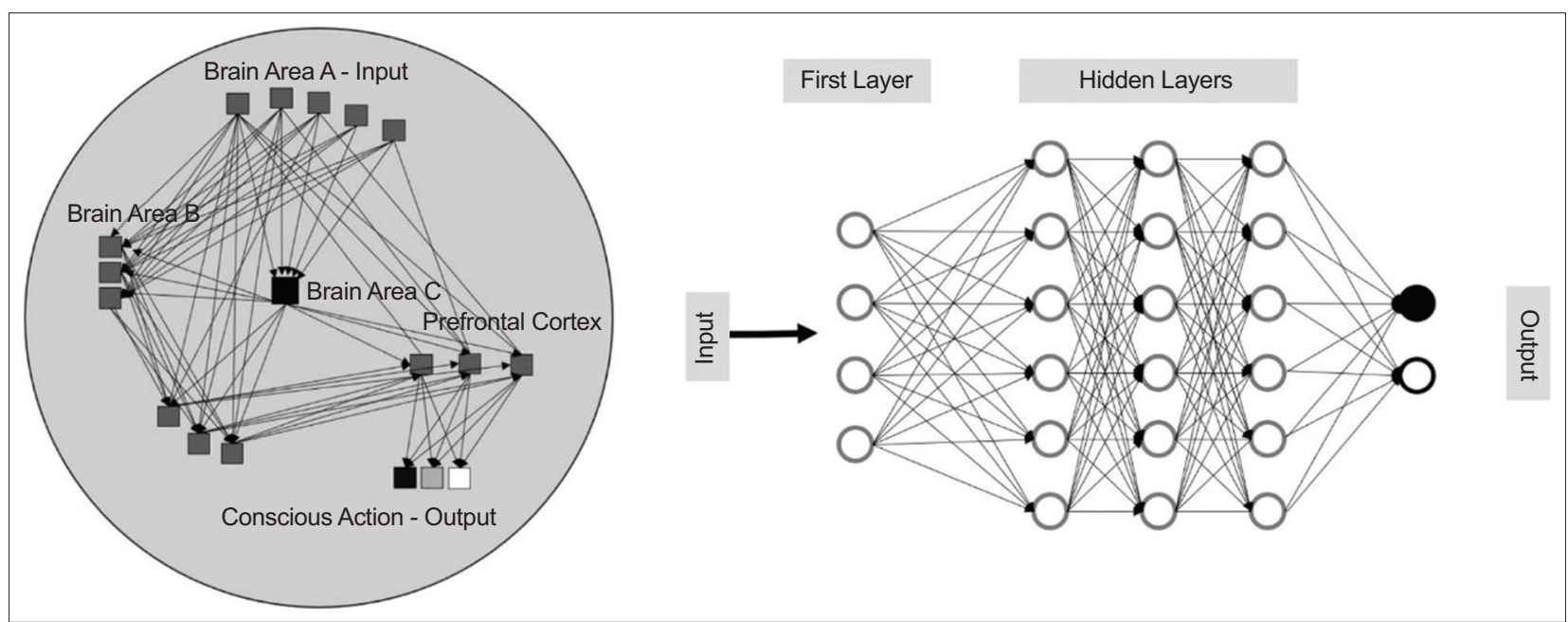

Figure 2 Similarities between an oversimplified human neural network and a convolutional neural network 
machine (SVM) model and obtained results similar to Lau, with a sensitivity greater than $80 \%$ in the detection of positive bleeding cases [25].

In 2009, Li et al took a database of 200 hemorrhage images from 10 patients and, using a multilayer perceptron (MLP) model, developed an ML algorithm capable of detecting areas of bleeding with a sensitivity, specificity and accuracy greater than $90 \%$. This study was particularly important because it was able to surpass the detection rate of the state-of-the-art methods at that time [26]. In the same year, Pan et al developed a CNN by analyzing the color and texture of the images. The algorithm was tested using 150 full videos of wireless capsule endoscopy (WCE), consisting of 3172 hemorrhage images and 11,458 of normal mucosa. This model achieved a sensitivity of $93 \%$ with a specificity of $96 \%$ for the detection of cases. The large number of images analyzed contributed to the robustness of this experiment [27].

In 2010, Charisis et al developed an SVM using a dataset of 40 images of normal mucosa and 40 images of ulcers. This model was able to detect positive cases with a sensitivity and specificity greater than $95 \%$. However, it was only able to detect cases of medium or higher severity, which reduces its applicability in real clinical practice [28].

In 2014, Fu et al developed a computer-aided design (CAD) method based on SVM, capable of detecting hemorrhage with a sensitivity, specificity and accuracy of $99 \%, 94 \%$ and $95 \%$, respectively. This method was particularly interesting because it introduced a new form of image analysis. The developed model analyzed super pixels-grouped sets of pixels of similar characteristics in each frame-which made it possible to reduce the computation costs compared to the analysis of each isolated pixel, while improving the detection capacity compared to the overall analysis of a frame [29]. In the same year, Gosh et al used 30 videos of WCE and, using 50 images of hemorrhage and 200 of normal mucosa for training the model, developed an SVM classifier applied to 2000 test images, achieving a sensitivity of $93 \%$ and specificity of $95 \%$ [30].

In December 2015, Hassan et al used 1200 training frames and 1720 testing frames to develop a new local texture descriptor that was capable of obtaining sensitivities and specificities above $98.9 \%$, significantly higher than what had been done to date. In addition, this method had a low computational cost, making it suitable for real-time implementation [31].

In 2018, Fan et al developed a method for simultaneous detection of ulcers and mucosal erosions, with a high accuracy of $95.2 \%$ and $95.3 \%$, sensitivity of $96.8 \%$ and $93.7 \%$, and specificity of $94.8 \%$ and $96.0 \%$ in detecting ulcers and erosions, respectively. This study was relevant since it did not evaluate an isolated lesion, but instead a set of pathological entities [32].

In January 2019, Leenhardt et al developed a CNN method capable of detecting small-bowel angiectasias, using 6360 still frames from 4166 different videocapsule videos. This study, given the large number of patients covered, proved to be extremely robust and presented excellent results, with a sensitivity of $100 \%$ and specificity of $96 \%$, an excellent starting point for future automated diagnostic software [33]. In fact, angiectasias are the most common lesions diagnosed in patients with medium GI bleeding undergoing video capsule endoscopy.

In August of 2019, Pokorelov et al developed a combined color and texture algorithm with excellent computational cost and efficiency. Using 300 bleeding frames and 200 nonbleeding or normal frames for the training dataset (500 frames) and 500 bleeding and 200 nonbleeding frames (700 frames) for the testing dataset, they were able to obtain a sensitivity, specificity and accuracy of $97.6 \%, 95.9 \%$ and $97.6 \%$, respectively [34]. Also, in August of the same year, Aoki et al developed a CNN method that compared the time and effectiveness of videocapsule reading by 2 processes: (A) endoscopist-alone readings; and (B) endoscopist readings after a first screening by the proposed CNN. Mean reading time of small-bowel sections by endoscopists was significantly shorter during process $\mathrm{B}$ (expert, $3.1 \mathrm{~min}$; trainee, $5.2 \mathrm{~min}$ ) compared to process A (expert, $12.2 \mathrm{~min}$; trainee, $20.7 \mathrm{~min})(\mathrm{P}<0.001)$. For 37 mucosal breaks, the detection rate by endoscopists was not significantly lower in process B (expert, $87 \%$; trainee, $55 \%$ ) compared to process A (expert, $84 \%$; trainee, $47 \%$ ). This study was extremely important because it demonstrates the applicability of these auxiliary diagnostic methods in daily clinical practice, enabling a significant reduction in the video capsule reading time [35].

More recently, in March 2020, Tsuboi et al used 2237 images of WCE and created a CNN system capable of detecting smallbowel angiectasias with a sensitivity of $98.8 \%$ and specificity of $98.4 \%$ [36]. In July 2020, Aoki et al developed a CNN using images from 41 patients, with a total of 27,847 images, capable of detecting blood in the intestinal lumen with a sensitivity of $96.6 \%$, specificity of $99.9 \%$ and accuracy of $99.9 \%$. The performance of the network was compared with a conventional tool (suspected blood indicator) and proved able to outperform this tool [37].

\section{Al and protuberant lesions}

One of the most profitable areas of investigation in this context is the detection and classification of protruding structures of the small intestine mucosa, since its analysis by other methods is extremely difficult. However, using videocapsule images it is also possible to detect abnormal structures present elsewhere in the GI tract.

In 2008, Barbosa et al, based on 100 images of normal mucosa and 92 images of tumor lesions and using an MLP method, developed an algorithm capable of being applied to real data, with a sensitivity of $98.7 \%$ and specificity of $96.6 \%$ in the detection of tumors of the small intestine [38]. The following year, using the same AI method, Li et al analyzed 300 video images from 2 WCE exams and developed a model with an accuracy of $86.1 \%$ (sensitivity and specificity of $89.8 \%$ ). The fact that they only used data from 2 patients limits the applicability of this model in other settings, such as real-life medical practice [39]. The same author, in April 2011, applying a model based on the color difference between tumor lesions and normal mucosa, used a dataset of 1200 images from 10 different patients to develop a CAD system that demonstrated a sensitivity of $82.3 \%$ 
and specificity of $84.7 \%$ in the detection of GI tumors through the analysis of WCE exams [40].

Barbosa et al also carried out a further study in 2011, with a more comprehensive dataset (700 tumor frames and 2300 normal frames). Through the analysis of mucosal textural information, they developed a method with sensitivity and specificity greater than $93 \%$ for the detection of tumors of the small intestine [41].

Zhao et al, in the same year, created a dataset of 1120 images (560 of polyps and 560 of normal mucosa), with the particularity of including a group of consecutive frames of injury and normal mucosa, to verify whether the simultaneous analysis of 5 frames of the same lesion is superior to the analysis of 1 isolated frame. This study was an important innovation, since until then most of the methods developed were based on the analysis of only one image of each lesion. Zhao demonstrated that a polyp sequence can have apparently normal frames and that a normal mucosa sequence can have apparently abnormal frames. By analyzing several consecutive frames, the number of false negatives and false positives in the model can be reduced. In this case, with the analysis of consecutive images, they managed to improve the specificity and sensitivity of single frame evaluation, from $91 \%$ and $83 \%$ to $95 \%$ and $92 \%$, respectively [42].

In August 2015, Vieira et al compared a method of SVM and one of MLP in the automatic detection of small intestine tumors, through the analysis of 700 abnormal frames from 14 patients and 2500 normal frames from 19 individuals, concluding that the MLP method is superior to the older AI method in sensitivity, specificity and accuracy [43]. In 2017, Yuan et al developed a CAD method capable of identifying polyps and also distinguishing other structures, such as bubbles and the presence of cloudy luminal material, with an accuracy greater than $95 \%$. This method is particularly important, since it allows the removal of luminal content that makes it difficult to evaluate images [44].

In March 2019, Blanes-Vidal et al managed to establish a correlation in 255 patients between the detection of colorectal polyps in colonoscopy and those detected in WCE in the same patients, with a sensitivity of $97.1 \%$ and specificity of $93.3 \%$. This study represents an important advance in the applicability of this technique as a possible method of screening for colorectal cancer in the future [45].

In February 2020, Saito et al, through the analysis of a robust database of 30,584 images of protruding small intestine lesions, developed a CNN method capable of not only identifying lesions but also classifying them as polyps, nodules, epithelial tumors, submucosal tumors and venous structures, with sensitivities of $86.5 \%, 92.0 \%, 95.8 \%, 77.0 \%$, and $94.4 \%$, respectively. This study was a pioneer in the use of several types of lesions in a single model, and allowed these methods to approach more closely to real clinical practice, where several pathological changes can occur simultaneously and require proper distinction [46].

\section{Al and inflammatory bowel disease}

Another medical field where the videocapsule has a well-established role is in the evaluation of patients with inflammatory bowel disease, particularly those with Crohn's disease (CD), since it allows an assessment of all the small intestine mucosa. In addition to being able to assist in the confirmation of the $\mathrm{CD}$ diagnosis, it also allows the extent of disease activity and response to therapy to be assessed, through the application of scores such as the Lewis score [47].

In 2010, Seshamani et al, using an SVM-based similarity learning method, used videocapsule images of 47 exams of CD patients, to manually extract 724 images of injury areas. In this way, they developed a model capable of detecting suggestive areas of injury with an accuracy of $88 \%$, which allowed to drastically reduce the training time of the model, without compromising its effectiveness [48].

In March 2020, Klang et al developed a deep-learning algorithm, using the analysis of 17,640 endoscopic capsule images from 49 patients with $\mathrm{CD}$ and healthy individuals, that achieved an accuracy greater than $95 \%$, revealing the potential of this technology in the prediction of small-bowel findings based on videocapsule endoscopy in CD patients [49]. Also, in March 2020, Freitas et al assessed the correlation between classic videocapsule reading and the use of a new software tool of the RAPID Reader ${ }^{\oplus}$, TOP100, in the application of the Lewis score in CD patients. They examined 115 patients and showed a strong agreement (89.6\% of the cases) between the 2 methods of capsule reading. This study is particularly important because it demonstrates the clinical applicability of this type of diagnostic aid [50].

More recently, in June 2020, Y. Barash, in collaboration with the aforementioned E. Klang, developed a neural network capable of classifying the severity of ulcers in patients with CD. To achieve that, they classified 2598 images containing ulcers on a numerical scale of 1-3. They divided the experiment into 2 parts. In the first part, they evaluated the interobserver agreement between 2 different evaluators, and in the second they used a CNN to automatically classify the ulcers. They obtained a global human interobserver agreement of 31\% (76\% for grade I-III ulcers) vs. a global neural network agreement of $67 \%$ (91\% for grade I-III) [51].

\section{Al and celiac disease}

Celiac disease affects around $1 \%$ of the world population, with an increasing prevalence in recent years. This chronic autoimmune disorder, characterized by an immune attack on the small intestine mucosa, is triggered by the ingestion of gluten in genetically susceptible individuals [52]. The gold standard for diagnosis is the presence of duodenal villous atrophy in endoscopic biopsies. However, this is an invasive and expensive procedure. Therefore, capsule endoscopy appears as a more practical approach in some settings and an alternative with fewer associated risks [52]. With the increasing use of this diagnostic method, computer models have been developed to assist doctors in diagnosing this disorder using a videocapsule enteroscopy video.

In 2010 Ciaccio et al developed a threshold classifier to classify images of patients with celiac disease. Using images 
from 21 exams (11 of patients with celiac disease and 10 controls) and through the analysis of 9 different characteristics of each frame, they developed a model capable of predicting the occurrence of the disease with a sensitivity of $80 \%$ and a specificity of $96 \%$. Later, in 2014 , the same investigation team developed a new model capable of predicting the occurrence of the disease with a sensitivity of $84.6 \%$ and specificity of $92.3 \%$, using base images from patients and controls [54].

In 2017, Zou et al, using data from 6 patients with celiac disease and 5 controls, developed a CNN to quantitatively measure the presence and degree of intestinal mucosa damage. Its model, using the latest technology in the field of AI, obtained a sensitivity and specificity of $100 \%$ in the small group tested. In addition, they were also able to classify the degree of mucosal injury, opening doors for the future analysis of a correlation between the videocapsule images and the histological evaluation [55].

More recently, Koh et al developed a computer-aided detection system, decomposing the video images of 13 control tests and 13 patients. This system, with an accuracy of $86.5 \%$ and a sensitivity and specificity of $88.4 \%$ and $84.6 \%$, respectively, demonstrates the potential to effectively identify patients with celiac disease [56].

In April 2020, Wang et al, using a deep learning method, developed a CNN system, based on data from 52 patients and 55 healthy controls, that demonstrated a remarkable accuracy (accuracy, sensitivity and specificity 95.9\%, 97.2\% and 95.6\%, respectively). This study was particularly robust given the large number of images collected, as well as the type of analysis used [57].

\section{Al and luminal content}

AI may also play a key role in locating the capsule in the GI tract, as well as in the detection and elimination of artifacts that may compromise the mucosal evaluation, thus reducing the required examination reading time and also reducing bias and interpretation errors. In 2012, Seguí et al developed a model capable of detecting, isolating and classifying luminal content, to remove it from image view. For this, he resorted to images of clean mucosa and images of luminal content, which they divided into turbid liquid and bubbles. The proposed system was then evaluated using a large dataset. The statistical analysis of the performance showed an accuracy above 90\%, far superior to that of previously existing models. In addition, this was the first work to distinguish between the different artifacts detected throughout the video capsule examination [58].

In 2013, Ionescu et al analyzed more than 10,000 frames from 10 different patients to detect images with artifacts and thus reduce the number of images that would have to be analyzed by the clinician, thus making the reading process faster and more effective. Through a CNN method, they managed to develop an algorithm with an accuracy of $88.2 \%$ in the detection of bubbles and food debris [59].

In 2018, Wang et al proposed to develop a model capable of automatically detecting the location of the boundaries between the stomach and the duodenum-pylorus. For this, they analyzed 42,000 images and randomly selected 3801 images from the pyloric region, 1822 pre-pyloric and 1979 postpyloric. Using an SVM method, the investigators were able to detect the location of the pylorus in 30 real WCE videos, with an accuracy of $97.1 \%$ and a specificity of $95.4 \%$ [60]. All these types of analysis can contribute greatly to the optimization of the evaluation of videocapsule images, to make the reading process less time consuming and considerably more effective.

\section{Al and hookworm}

Parasitic infections represent another type of pathological entity that can be detected by this diagnostic method. Of all the parasites that reach the GI tract, hookworm infection is one of the most common and serious, affecting about 600 million people worldwide. The hookworm is a helminth that presents itself as a tubular structure, with grayish, white or pinkish semi-transparent body [61].

In March 2016, Xiao et al used 440,000 images from 11 patients to develop a mechanism capable of automatically detecting these helminths in videocapsule images. This was one of the first studies to address this topic. Its model showed a sensitivity and specificity close to $78 \%$. The low effectiveness of this model is mainly due to the difficulty in correctly distinguishing the parasite's structure from some bubbles and intestinal folds. As a way of correcting this low performance, they raise the possibility of considering the temporal and spatial relationship between consecutive images in future works [62]. In May 2018, He et al used 1500 images to create a $\mathrm{CNN}$ model capable of detecting the presence of hookworms with a sensitivity of $84.6 \%$ and specificity of $88.6 \%$; these results were superior to those previously obtained in this area [63].

The automatic detection of this type of parasite remains a very challenging task, since the wide variety of aspects that they can present is a huge obstacle to the development of effective methods for their detection. Thus, it will be necessary to develop more research in order to improve the accuracy of these methods in the detection of intestinal helminths. Although there are alternative tests available, such as the parasitological examination of the stools, this task remains an important proof of concept for AI in video capsule endoscopy. A summary of all the studies discussed can be found in Table 1.

\section{Al: promises and pitfalls}

In several studies AI was able to compensate for the limited experience of novice endoscopists and some errors by even the most experienced endoscopists. Human nature makes their performance variable, and diagnostic performance may certainly be impaired by a decrease of awareness and attention, or forgetfulness due to fatigue, anxiety, or any other physical or emotional stress [64]. The scarcity of human resources and the increasing workload can be alleviated with the implementation of AI systems. AI may also have a particularly important role in the emergency department, where less time 
Table 1 Summary of studies using AI methods to aid videocapsule video analysis

\begin{tabular}{|c|c|c|c|c|c|c|}
\hline Reference & $\begin{array}{l}\text { Field of } \\
\text { application }\end{array}$ & $\begin{array}{c}\text { Year of } \\
\text { publication }\end{array}$ & Proposed goals & $\begin{array}{l}\text { Number of } \\
\text { subjects }\end{array}$ & AI type & Results \\
\hline $\begin{array}{l}\text { Ciaccio } \\
\text { et al [54] }\end{array}$ & Celiac disease & 2010 & $\begin{array}{l}\text { Evaluate if } \\
\text { quantitative markers } \\
\text { could assist in the } \\
\text { screening for celiac } \\
\text { disease }\end{array}$ & $\begin{array}{l}11 \text { patients and } \\
10 \text { controls }\end{array}$ & $\begin{array}{l}\text { Threshold classifier } \\
\text { (quantitative analysis } \\
\text { of } 9 \text { different frame } \\
\text { characteristics) }\end{array}$ & $\begin{array}{l}\text { Sensitivity of } 80 \% \text { and } \\
\text { a specificity of } 96 \% \text { in } \\
\text { predicting the occurrence of } \\
\text { the disease }\end{array}$ \\
\hline $\begin{array}{l}\text { Ciaccio } \\
\text { et al [54] }\end{array}$ & Celiac disease & 2014 & $\begin{array}{l}\text { Improve the image- } \\
\text { based detection of } \\
\text { villous atrophy and } \\
\text { other abnormality } \\
\text { in videocapsule } \\
\text { endoscopy, using the } \\
\text { grayscale brightness } \\
\text { of each frame }\end{array}$ & $\begin{array}{l}13 \text { patients and } \\
13 \text { controls }\end{array}$ & $\begin{array}{l}\text { Threshold classifier } \\
\text { (quantitative } \\
\text { analysis of grayscale } \\
\text { brightness) }\end{array}$ & $\begin{array}{l}\text { Sensitivity of } 84.6 \% \text { and } \\
\text { specificity of } 92.3 \%\end{array}$ \\
\hline Zou et al [55] & Celiac disease & 2017 & $\begin{array}{l}\text { Measure the presence } \\
\text { and degree of } \\
\text { intestinal mucosa } \\
\text { damage }\end{array}$ & $\begin{array}{l}6 \text { patients and } 6 \\
\text { controls }\end{array}$ & $\mathrm{CNN}$ & $\begin{array}{l}\text { Sensitivity and specificity } \\
\text { of } 100 \% \text { in the cases tested. } \\
\text { They were also capable } \\
\text { to classify the degree of } \\
\text { mucosal damage }\end{array}$ \\
\hline Koh et al [56] & Celiac disease & 2019 & $\begin{array}{l}\text { Identify patients with } \\
\text { celiac disease }\end{array}$ & $\begin{array}{l}13 \text { patients and } \\
13 \text { controls }\end{array}$ & SVM & $\begin{array}{l}\text { Accuracy of } 86.5 \% \text { and a } \\
\text { sensitivity and specificity } \\
\text { of } 88.4 \% \text { and } 84.6 \% \\
\text { respectively }\end{array}$ \\
\hline $\begin{array}{l}\text { Wang } \\
\text { et al [57] }\end{array}$ & Celiac disease & 2020 & $\begin{array}{l}\text { Identify patients with } \\
\text { celiac disease }\end{array}$ & $\begin{array}{l}52 \text { patients and } \\
55 \text { controls }\end{array}$ & $\mathrm{CNN}$ & $\begin{array}{l}\text { Accuracy of } 95.9 \% \text {, } \\
\text { sensitivity of } 97.2 \% \text { and } \\
\text { specificity of } 95.6 \%\end{array}$ \\
\hline $\begin{array}{l}\text { Seshamani } \\
\text { et al [48] }\end{array}$ & $\begin{array}{l}\text { Inflammatory } \\
\text { bowel disease }\end{array}$ & 2010 & $\begin{array}{l}\text { Detecting suggestive } \\
\text { areas of Crohn's } \\
\text { disease injury }\end{array}$ & 47 exams & SVM & Accuracy of $88 \%$ \\
\hline $\begin{array}{l}\text { Klang e } \\
\text { tal [49] }\end{array}$ & $\begin{array}{l}\text { Inflammatory } \\
\text { bowel disease }\end{array}$ & 2020 & $\begin{array}{l}\text { Detecting suggestive } \\
\text { areas of Crohn's } \\
\text { disease injury }\end{array}$ & 49 exams & $\begin{array}{l}\text { Deep learning } \\
\text { algorithm }\end{array}$ & Accuracy greater than $95 \%$ \\
\hline $\begin{array}{l}\text { Freitas } \\
\text { et al [50] }\end{array}$ & $\begin{array}{l}\text { Inflammatory } \\
\text { bowel disease }\end{array}$ & 2020 & $\begin{array}{l}\text { Assess the correlation } \\
\text { between classic } \\
\text { videocapsule reading } \\
\text { and the use of a } \\
\text { new software tool in } \\
\text { patients with CD }\end{array}$ & 115 patients & NA & $\begin{array}{l}\text { Agreement on } 89.6 \% \text { of the } \\
\text { cases between the } 2 \text { methods }\end{array}$ \\
\hline $\begin{array}{l}\text { Barash } \\
\text { et al }[51]\end{array}$ & $\begin{array}{l}\text { Inflammatory } \\
\text { bowel disease }\end{array}$ & 2020 & $\begin{array}{l}\text { Access the } \\
\text { interobserver } \\
\text { agreement between } 2 \\
\text { human observers and } \\
\text { a neural network }\end{array}$ & 49 exams & $\begin{array}{l}\text { Ordinary neural } \\
\text { network }\end{array}$ & $\begin{array}{l}\text { Global human interobserver } \\
\text { agreement of } 31 \% \text { ( } 76 \% \\
\text { between grade I-III ulcers) } \\
\text { vs. a global neural network } \\
\text { agreement of } 67 \% \text { ( } 91 \% \\
\text { between grade I-III) }\end{array}$ \\
\hline Xiao et al [62] & $\begin{array}{l}\text { Hookworm } \\
\text { infection }\end{array}$ & 2016 & $\begin{array}{l}\text { Automatically detect } \\
\text { hookworms in WCE } \\
\text { videos }\end{array}$ & 11 patients & Rusboost method & $\begin{array}{l}\text { Sensitivity and specificity } \\
\text { close to } 78 \%\end{array}$ \\
\hline He et al [63] & $\begin{array}{l}\text { Hookworm } \\
\text { infection }\end{array}$ & 2018 & $\begin{array}{l}\text { Detect hookworm } \\
\text { presence }\end{array}$ & 1500 images & $\mathrm{CNN}$ & $\begin{array}{l}\text { Sensitivity of } 84.6 \% \text { and } \\
\text { specificity of } 88.6 \%\end{array}$ \\
\hline Segui et al [58] & $\begin{array}{l}\text { Luminal } \\
\text { content }\end{array}$ & 2012 & Detect video artefacts & Large dataset & NA & $\begin{array}{l}\text { Accuracy above } 90 \% \text { - first } \\
\text { work to distinguish between } \\
\text { the different artifacts }\end{array}$ \\
\hline $\begin{array}{l}\text { Wang } \\
\text { et al [59] }\end{array}$ & $\begin{array}{l}\text { Capsule } \\
\text { location }\end{array}$ & 2018 & $\begin{array}{l}\text { Detect pylorus } \\
\text { location }\end{array}$ & $\begin{array}{l}3801 \text { images from } \\
\text { the pyloric region }\end{array}$ & SVM & $\begin{array}{l}\text { Accuracy of } 97.1 \% \text { and } \\
\text { specificity of } 95.4 \%\end{array}$ \\
\hline
\end{tabular}


Table 1 (Continued)

\begin{tabular}{|c|c|c|c|c|c|c|}
\hline Reference & $\begin{array}{l}\text { Field of } \\
\text { application }\end{array}$ & $\begin{array}{c}\text { Year of } \\
\text { publication }\end{array}$ & Proposed goals & $\begin{array}{l}\text { Number of } \\
\text { subjects }\end{array}$ & AI type & Results \\
\hline $\begin{array}{l}\text { Barbosa } \\
\text { et al [38] }\end{array}$ & $\begin{array}{l}\text { Protruding } \\
\text { structures }\end{array}$ & 2008 & $\begin{array}{l}\text { Small intestine tumor } \\
\text { detection }\end{array}$ & $\begin{array}{l}100 \text { images of } \\
\text { normal mucosa } \\
\text { and } 92 \text { images of } \\
\text { tumor lesions }\end{array}$ & MLP & $\begin{array}{l}\text { Sensitivity of } 98.7 \% \text { and } \\
\text { specificity of } 96.6 \%\end{array}$ \\
\hline Li et al [39] & $\begin{array}{l}\text { Protruding } \\
\text { structures }\end{array}$ & 2009 & $\begin{array}{l}\text { Small intestine tumor } \\
\text { detection }\end{array}$ & $\begin{array}{l}\text { WCE videos from } \\
2 \text { patients }\end{array}$ & MLP & $\begin{array}{l}\text { Accuracy of } 86.1 \% \text {, } \\
\text { sensitivity of } 89.8 \% \text { and } \\
\text { specificity of } 89.8 \%\end{array}$ \\
\hline Li et al [40] & $\begin{array}{l}\text { Protruding } \\
\text { structures }\end{array}$ & 2011 & GI tumor detection & 10 patients & SVM & $\begin{array}{l}\text { Sensitivity of } 82.3 \% \text { and } \\
\text { specificity of } 84.7 \%\end{array}$ \\
\hline $\begin{array}{l}\text { Barbosa } \\
\text { et al [41] }\end{array}$ & $\begin{array}{l}\text { Protruding } \\
\text { structures }\end{array}$ & 2012 & $\begin{array}{l}\text { Small intestine tumor } \\
\text { detection }\end{array}$ & $\begin{array}{l}700 \text { tumor frames } \\
\text { and } 2300 \text { normal } \\
\text { frames }\end{array}$ & MLP & $\begin{array}{l}\text { Sensitivity and specificity } \\
\text { greater than } 93 \%\end{array}$ \\
\hline Zhao et al [42] & $\begin{array}{l}\text { Protruding } \\
\text { structures }\end{array}$ & 2012 & $\begin{array}{l}\text { Verify if using } \\
\text { consecutive frames } \\
\text { from the same lesion } \\
\text { was more effective } \\
\text { than single frame } \\
\text { analysis }\end{array}$ & $\begin{array}{l}560 \text { polyp frames } \\
\text { and } 560 \text { normal } \\
\text { mucosa frames }\end{array}$ & NA & $\begin{array}{l}\text { Managed to increase the } \\
\text { specificity and sensitivity } \\
\text { of single frame evaluation } \\
\text { from } 91 \% \text { and } 83 \% \text { to } 95 \% \\
\text { and } 92 \% \text { with the analysis of } \\
\text { consecutive images }\end{array}$ \\
\hline $\begin{array}{l}\text { Vieira } \\
\text { et al }[43]\end{array}$ & $\begin{array}{l}\text { Protruding } \\
\text { structures }\end{array}$ & 2015 & $\begin{array}{l}\text { Compare a method } \\
\text { of SVM and one of } \\
\text { MLP in the automatic } \\
\text { detection of small } \\
\text { intestine tumors }\end{array}$ & $\begin{array}{l}700 \text { abnormal } \\
\text { and } 2500 \text { normal } \\
\text { frames from } 19 \\
\text { patients }\end{array}$ & MLP vs. SVM & $\begin{array}{l}\text { The MLP method was } \\
\text { superior to the older AI } \\
\text { method in sensitivity, } \\
\text { specificity and accuracy }\end{array}$ \\
\hline Yuan et al [44] & $\begin{array}{l}\text { Protruding } \\
\text { structures }\end{array}$ & 2017 & $\begin{array}{l}\text { Detect polyps and } \\
\text { distinguish it from } \\
\text { other structures }\end{array}$ & $\begin{array}{l}3000 \text { normal } \\
\text { mucosa frames } \\
\text { and } 1000 \text { polyps }\end{array}$ & $\begin{array}{l}\text { Stacked Sparse } \\
\text { Autoencoder with } \\
\text { Image Manifold } \\
\text { Constraint (SSAEIM) }\end{array}$ & Accuracy greater than $95 \%$ \\
\hline $\begin{array}{l}\text { Blaines-Vidal } \\
\text { et al [45] }\end{array}$ & $\begin{array}{l}\text { Protruding } \\
\text { structures }\end{array}$ & 2019 & $\begin{array}{l}\text { Establish a match } \\
\text { between the colorectal } \\
\text { polyps detected in } \\
\text { colonoscopy and } \\
\text { those detected in } \\
\text { WCE }\end{array}$ & 255 patients & $\mathrm{CNN}$ & $\begin{array}{l}\text { Accuracy of } 96.4 \% \text {, } \\
\text { sensitivity of } 97.1 \% \text { ) and } \\
\text { specificity of } 93.3 \%\end{array}$ \\
\hline Saito et al [46] & $\begin{array}{l}\text { Protruding } \\
\text { structures }\end{array}$ & 2020 & $\begin{array}{l}\text { Identify lesions but } \\
\text { also classify them as } \\
\text { polyps, nodules, } \\
\text { Epithelial tumors, } \\
\text { submucosal tumors } \\
\text { and venous structures }\end{array}$ & $\begin{array}{l}30,584 \text { images of } \\
\text { protruding small } \\
\text { intestine lesions }\end{array}$ & $\mathrm{CNN}$ & $\begin{array}{l}\text { Sensitivities of } 86.5 \%, 92.0 \% \text {, } \\
95.8 \%, 77.0 \% \text {, and } 94.4 \% \\
\text { for the different types of } \\
\text { structures }\end{array}$ \\
\hline Lau et al [24] & $\begin{array}{l}\text { GI } \\
\text { hemorrhage }\end{array}$ & 2007 & $\begin{array}{l}\text { Detect the presence of } \\
\text { GI hemorrhage using } \\
\text { a simple color coding }\end{array}$ & $\begin{array}{l}577 \text { abnormal } \\
\text { images }\end{array}$ & NA & Sensitivity of $88.3 \%$ \\
\hline $\begin{array}{l}\text { Giritharan } \\
\text { et al [25] }\end{array}$ & $\begin{array}{l}\text { GI } \\
\text { hemorrhage }\end{array}$ & 2008 & $\begin{array}{l}\text { Detect the presence of } \\
\text { GI hemorrhage }\end{array}$ & $\begin{array}{l}400 \text { GI bleeding } \\
\text { frames }\end{array}$ & SVM & Sensitivity greater than $80 \%$ \\
\hline Li et al [26] & $\begin{array}{l}\text { GI } \\
\text { hemorrhage }\end{array}$ & 2009 & $\begin{array}{l}\text { Detect the presence of } \\
\text { GI hemorrhage }\end{array}$ & $\begin{array}{l}10 \text { patients ( } 200 \\
\text { bleeding frames) }\end{array}$ & MLP & $\begin{array}{l}\text { Sensitivity, specificity and } \\
\text { accuracy greater than } 90 \%\end{array}$ \\
\hline Pan et al [27] & $\begin{array}{l}\text { GI } \\
\text { hemorrhage }\end{array}$ & 2009 & $\begin{array}{l}\text { Detect the presence } \\
\text { of GI hemorrhage } \\
\text { analyzing the color } \\
\text { and texture }\end{array}$ & $\begin{array}{l}150 \text { full WCE } \\
\text { videos }\end{array}$ & $\mathrm{CNN}$ & $\begin{array}{l}\text { Sensitivity of } 93 \% \text { with a } \\
\text { specificity of } 96 \% \text { for the } \\
\text { detection of cases }\end{array}$ \\
\hline $\begin{array}{l}\text { Charisis } \\
\text { et al [28] }\end{array}$ & $\begin{array}{l}\text { GI } \\
\text { hemorrhage }\end{array}$ & 2010 & Detect GI ulcers & $\begin{array}{l}40 \text { normal } \\
\text { mucosa and } 40 \\
\text { ulcer images }\end{array}$ & SVM & $\begin{array}{l}\text { Sensitivity and specificity } \\
\text { greater than } 95 \% \text { (only } \\
\text { cases of medium or higher } \\
\text { severity) }\end{array}$ \\
\hline
\end{tabular}


Table 1 (Continued)

\begin{tabular}{|c|c|c|c|c|c|c|}
\hline Reference & $\begin{array}{l}\text { Field of } \\
\text { application }\end{array}$ & $\begin{array}{c}\text { Year of } \\
\text { publication }\end{array}$ & Proposed goals & $\begin{array}{l}\text { Number of } \\
\text { subjects }\end{array}$ & AI type & Results \\
\hline Fu et al [29] & $\begin{array}{l}\text { GI } \\
\text { hemorrhage }\end{array}$ & 2014 & $\begin{array}{l}\text { Detect GI bleeding } \\
\text { using super pixel } \\
\text { analysis }\end{array}$ & $\begin{array}{l}20 \text { different WCE } \\
\text { videos }\end{array}$ & SVM & $\begin{array}{l}\text { Sensitivity, specificity and } \\
\text { accuracy of } 99 \% ; 94 \% \text { and } \\
95 \% \text { respectively }\end{array}$ \\
\hline Gosh et al [30] & $\begin{array}{l}\text { GI } \\
\text { hemorrhage }\end{array}$ & 2014 & Detect GI bleeding & 30 WCE videos & SVM & $\begin{array}{l}\text { Sensitivity of } 93 \% \text {, specificity } \\
94.9 \%\end{array}$ \\
\hline $\begin{array}{l}\text { Hassan } \\
\text { et al [31] }\end{array}$ & $\begin{array}{l}\text { GI } \\
\text { hemorrhage }\end{array}$ & 2015 & Detect GI bleeding & $\begin{array}{l}1200 \text { training } \\
\text { frames and } 1720 \\
\text { testing frames }\end{array}$ & SVM & $\begin{array}{l}\text { Sensitivity and specificity } \\
\text { above } 98.9 \%\end{array}$ \\
\hline Fan et al [32] & $\begin{array}{l}\text { GI } \\
\text { hemorrhage }\end{array}$ & 2018 & $\begin{array}{l}\text { Simultaneous } \\
\text { detection of ulcers } \\
\text { and mucosal erosions }\end{array}$ & $\begin{array}{l}144 \text { full WCE } \\
\text { videos }\end{array}$ & $\begin{array}{l}\text { CAD method based } \\
\text { on deep learning } \\
\text { framework }\end{array}$ & $\begin{array}{l}\text { Accuracy of } 95.2 \% \text { and } \\
95.3 \% \text {, sensitivity of } 96.8 \% \\
\text { and } 93.7 \% \text {, and specificity } \\
\text { of } 94.8 \% \text { and } 95.9 \% \text {, in } \\
\text { detecting ulcers and erosions } \\
\text { respectively }\end{array}$ \\
\hline $\begin{array}{l}\text { Leenhardt } \\
\text { et al [33] }\end{array}$ & $\begin{array}{l}\text { GI } \\
\text { hemorrhage }\end{array}$ & 2019 & $\begin{array}{l}\text { Detecting small bowel } \\
\text { angiectasias }\end{array}$ & $\begin{array}{l}6360 \text { still } \\
\text { frames from } \\
4166 \text { different } \\
\text { videocapsule } \\
\text { videos }\end{array}$ & $\mathrm{CNN}$ & $\begin{array}{l}\text { Sensitivity of } 100 \% \text { and } \\
\text { specificity of } 96 \%\end{array}$ \\
\hline $\begin{array}{l}\text { Pokorelov } \\
\text { et al [34] }\end{array}$ & $\begin{array}{l}\text { GI } \\
\text { hemorrhage }\end{array}$ & 2019 & $\begin{array}{l}\text { Develop a color and } \\
\text { texture algorithm } \\
\text { with excellent } \\
\text { computational costs }\end{array}$ & $\begin{array}{l}500 \text { frames for } \\
\text { the training } \\
\text { dataset and } 700 \\
\text { frames for the } \\
\text { testing dataset }\end{array}$ & SVM & $\begin{array}{l}\text { Sensitivity, specificity and } \\
\text { accuracy of } 97.6 \%, 95.9 \% \\
\text { and } 97.6 \%\end{array}$ \\
\hline Aoki et al [35] & $\begin{array}{l}\text { GI } \\
\text { hemorrhage }\end{array}$ & 2019 & $\begin{array}{l}\text { Compare the time } \\
\text { and effectiveness of } \\
\text { videocapsule reading } \\
\text { by endoscopist-alone } \\
\text { and endoscopist } \\
\text { readings after the } \\
\text { first screening by a } \\
\text { proposed CNN }\end{array}$ & NA & $\mathrm{CNN}$ & $\begin{array}{l}\text { Mean reading time was } \\
\text { significantly shorter during } \\
\text { the second process without } \\
\text { significantly decreasing in } \\
\text { the detection rate }\end{array}$ \\
\hline $\begin{array}{l}\text { Tsuboi } \\
\text { et al [36] }\end{array}$ & $\begin{array}{l}\text { GI } \\
\text { hemorrhage }\end{array}$ & 2020 & $\begin{array}{l}\text { Detect small bowel } \\
\text { angiectasis }\end{array}$ & $\begin{array}{l}2237 \text { WCE } \\
\text { images }\end{array}$ & $\mathrm{CNN}$ & $\begin{array}{l}\text { Sensitivity of } 98.8 \% \text { and } \\
\text { specificity of } 98.4 \%\end{array}$ \\
\hline Aoki et al [37] & $\begin{array}{l}\text { GI } \\
\text { hemorrhage }\end{array}$ & 2020 & Detect GI bleeding & $\begin{array}{l}41 \text { patients, with } \\
\text { a total of } 27847 \\
\text { images }\end{array}$ & $\mathrm{CNN}$ & $\begin{array}{l}\text { Sensitivity of } 96.6 \% \text {, } \\
\text { specificity of } 99.9 \% \text { and } \\
\text { accuracy of } 99.9 \%\end{array}$ \\
\hline
\end{tabular}

AI, artificial intelligence; CAD, computer aided design; CNN, convolutional neural network; GI, gastrointestinal; $M L$, machine learning;

$M L P$, multilayer perceptron; NA, not applicable; SVM, support-vector machine; WCE, wireless capsule endoscopy

is available for full capsule visualization and a faster view time is often necessary.

Despite convincing results and growing evidence of the central role of $\mathrm{AI}$ in technological evolution in the area of digestive endoscopy, the overwhelming majority of studies were designed in a retrospective manner. Furthermore, inherent bias, such as selection bias, cannot be excluded in this situation and real-life clinical application should be carefully tested and taken into consideration before validation of the AI solution.

Spectrum bias is another pitfall of the current AI application to capsule endoscopy. Spectrum bias occurs when a diagnostic test is studied in a range of individuals who are different from the intended population for the test. AI systems are tailor-made, designed to fit the training dataset, and the risk of overfitting should not be ignored. As a matter of fact, the efficiency and validity of an AI learning model may not be completely applicable to a new dataset, and AI learning models are still vulnerable to overfitting issues despite recent mitigation efforts.

On the other hand, the efficiency and accuracy of ML increases as the amount of data increases. Capsule endoscopy produces a considerable quantity of data to feed the growth of the ML systems. Additionally, the advent of the big data era will inexorably propel the exponential development of AI in capsule endoscopy. Despite the many challenges, the fast development of AI will ensure a relevant role for AI in capsule endoscopy in clinical practice. 


\section{Concluding remarks}

The exponential development of the computational capacity of new computers, coupled with a greater understanding and accessibility of deep learning technologies, has made it possible to develop algorithms that are increasingly effective and applicable in the most diverse areas. Health, and particularly gastroenterology, are no exception. Undoubtedly, the future of the analysis of capsule endoscopy videos involves the use of auxiliary computerized methods that will not only facilitate the analysis of these images, but also improve the accuracy of diagnosis.

However, there is a pressing need for more research studies proving the usefulness of this technology in a clinical context, taking into account the computational costs, efficiency and accuracy of the technology. Indeed, there is still a long way to go before AI takes its place as an integral part of the daily clinical practice of the gastroenterologist.

\section{References}

1. Yu K, Beam AL, Kohane IS. Artificial intelligence in healthcare. Nat Biomed Eng 2018;2:719-931.

2. Hosny A, Parmar C, Quackenbush J, et al. Artificial intelligence in radiology. Nat Rev Cancer 2018;18:500-510.

3. Pinto dos Santos D, Giese D, Brodehl S, et al. Medical students' attitude towards artificial intelligence: a multicentre survey. Eur Radiol 2019;29:1640-1646.

4. Amisha, Malik P, Pathania $\mathrm{M}$, et al. Overview of artificial intelligence in medicine. J Family Med Prim Care 2019;8:23282331.

5. Ashrafian H, Darzi A, Athanasiou T. A novel modification of the Turing test for artificial intelligence and robotics in healthcare. Int J Med Robotics Comput Assist Surg 2015;11:38-43.

6. CB Insights. Healthcare Remains The Hottest AI Category For Deals [Internet]. CB Insights Research. CBInsights;2018 [cited2020Jun21]. Available from: https://www.cbinsights.com/ research/artificial-intelligence-healthcare-startups-investors

7. Le Berre C, Sandborn WJ, Aridhi S, et al. Application of artificial intelligence to gastroenterology and hepatology. Gastroenterology 2020;158:76-94.e2.

8. Yang YJ, Bang CS. Application of artificial intelligence in gastroenterology. WJG 2019;25:1666-1683.

9. Erickson BJ, Korfiatis P, Akkus Z, et al. Machine learning for medical imaging. RadioGraphics 2017;37:505-515.

10. Cabitza F, Banfi G. Machine learning in laboratory medicine: waiting for the flood?. Clin Chem Lab Med 2018;56:516-524.

11. Vamathevan J, Clark D, Czodrowski P, et al. Applications of machine learning in drug discovery and development. Nat Rev Drug Discov 2019;18:463-477.

12. DeGregory KW, Kuiper P, DeSilvio T, et al. A review of machine learning in obesity. Obes Rev 2018;19:668-685.

13. Handelman GS, Kok HK, Chandra RV, et al. eDoctor: machine learning and the future of medicine. J Intern Med 2018;284:603619.

14. Rashidi HH, Tran NK, Betts EV, et al. Artificial intelligence and machine learning in pathology: the present landscape of supervised methods. Acad Pathol 2019;6:1-17.

15. Naqa IE, Li R, Murphy MJ. Machine learning in radiation oncology: theory and Applications. Cham: Springer; 2015.
16. Cleret de Langavant L, Bayen E, Yaffe K. Unsupervised machine learning to identify high likelihood of dementia in populationbased surveys: development and validation study. J Med Internet Res 2018;20:e10493.

17. Chassagnon G, Vakalopolou M, Paragios N, et al. Deep learning: definition and perspectives for thoracic imaging. Eur Radiol 2020;30:2021-2030.

18. LeCun Y, Bengio Y, Hinton G. Deep learning. Nature 2015;521:436444.

19. Matsugu M, Mori K, Mitari Y, et al. Subject independent facial expression recognition with robust face detection using a convolutional neural network. Neural Netw 2003;16:555-559.

20. Li N, Zhao X, Yang Y, Zou X. Objects classification by learningbased visual saliency model and convolutional neural network. Comput Intell Neurosci 2016;2016:1-12.

21. Kim J, Kim J, Jang G, et al. Fast learning method for convolutional neural networks using extreme learning machine and its application to lane detection. Neural Netw 2017;87:109-121.

22. Anwar SM, Majid M, Qayyum A, et al. Medical image analysis using convolutional neural networks: a review. J Med Syst 2018;42:226

23. Soffer S, Klang E, Shimon O, et al. Deep learning for wireless capsule endoscopy: a systematic review and meta-analysis. Gastrointest Endosc 2020;92:831-839.

24. Lau PY, Correia PL. Detection of bleeding patterns in WCE video using multiple features. Conference proceedings: Annual International Conference of the IEEE Eng Med Bio Soc. IEEE Engineering in Medicine and Biology Society. Annual Conference 2007;2007:5601-5604.

25. Giritharan B, Yuan X, Liu J, et al. Bleeding detection from capsule endoscopy videos. Conference proceedings: Annual International Conference of the IEEE Engineering in Medicine and Biology Society. IEEE Eng Med Bio Soc. Annual Conference 2008;2008:47804783.

26. Li B, Meng MQ. Computer-aided detection of bleeding regions for capsule endoscopy images. IEEE transactions on bio-medical engineering 2009;56:1032-1039.

27. Pan G, Yan G, Song X, et al. BP neural network classification for bleeding detection in wireless capsule endoscopy. J Med Eng Technol 2009;33:575-581.

28. Charisis V, Hadjileontiadis LJ, Liatsos CN, et al. Abnormal pattern detection in wireless capsule endoscopy images using nonlinear analysis in RGB color space. IEEE Eng Med Bio Soc. Annual Conference 2010;2010:3674-3677.

29. Fu Y, Zhang W, Mandal M, et al. Computer-aided bleeding detection in WCE video. IEEE J Biomed Health Inform 2014;18:636-642.

30. Ghosh T, Fattah SA, Shahnaz C, et al. An automatic bleeding detection scheme in wireless capsule endoscopy based on histogram of an RGB-indexed image. IEEE Eng Med Bio Soc. Annual Conference 2014;2014:4683-4686.

31. Hassan AR, Haque MA. Computer-aided gastrointestinal hemorrhage detection in wireless capsule endoscopy videos. Comput Methods Programs Biomed 2015;122:341-353.

32. Fan S, Xu L, Fan Y, et al. Computer-aided detection of small intestinal ulcer and erosion in wireless capsule endoscopy images. Phys. Med. Biol 2018;63:165001.

33. Leenhardt R, Vasseur P, Li C, et al. A neural network algorithm for detection of GI angiectasia during small-bowel capsule endoscopy. Gastrointest Endosc 2019;89:189-194.

34. Pogorelov K, Suman S, Azmadi Hussin F, et al. Bleeding detection in wireless capsule endoscopy videos - Color versus texture features. J Appl Clin Med Phys 2019;20:141-154.

35. Aoki T, Yamada A, Aoyama K, et al. Clinical usefulness of a deep learning-based system as the first screening on small-bowel capsule endoscopy reading. Dig Endosc 2020;32:585-591.

36. Tsuboi A, Oka S, Aoyama, et al. Artificial intelligence using a 
convolutional neural network for automatic detection of smallbowel angioectasia in capsule endoscopy images. Dig Endosc 2020;32:382-390.

37. Aoki T, Yamada A, Kato Y, et al. Automatic detection of blood content in capsule endoscopy images based on a deep convolutional neural network. J Gastroenterol Hepatol 2020;35:1196-1200.

38. Barbosa DJ, Ramos J, Lima CS. Detection of small bowel tumors in capsule endoscopy frames using texture analysis based on the discrete wavelet transform. Conf Proc IEEE Eng Med Biol Soc 2008;2008:3012-3015.

39. Li B, Meng MQ, Xu L. A comparative study of shape features for polyp detection in wireless capsule endoscopy images. Conf Proc IEEE Eng Med Biol Soc 2009;2009:3731-3734.

40. Li BP, Meng MQ. Comparison of several texture features for tumor detection in CE images. J Med Syst 2012;36:2463-2469.

41. Barbosa DC, Roupar DB, Ramos JC, et al. Automatic small bowel tumor diagnosis by using multi-scale wavelet-based analysis in wireless capsule endoscopy images. Biomed Eng Online 2012;11:3.

42. Zhao Q, Dassopoulos T, Mullin G, et al. Towards integrating temporal information in capsule endoscopy image analysis. IEEE Eng Med Biol Soc Annual Conference 2011;2011:6627-6630.

43. Vieira PM, Ramos J, Lima CS. Automatic detection of small bowel tumors in endoscopic capsule images by ROI selection based on discarded lightness information. IEEE Eng Med Biol Soc. Annual Conference 2015;2015:3025-3028.

44. Yuan Y, Meng MQ. Deep learning for polyp recognition in wireless capsule endoscopy images. Medical Physics 2017;44:1379-1389.

45. Blanes-Vidal V, Baatrup G, Nadimi ES. Addressing priority challenges in the detection and assessment of colorectal polyps from capsule endoscopy and colonoscopy in colorectal cancer screening using machine learning. Acta Oncol (Stockholm, Sweden) 2019;58:S29-S36.

46. Saito H, Aoki T, Aoyama K, et al. Automatic detection and classification of protruding lesions in wireless capsule endoscopy images based on a deep convolutional neural network. Gastrointest Endosc 2020;94:144-151.

47. Kalla R, McAlindon ME, Drew K, et al. Clinical utility of capsule endoscopy in patients with Crohn's disease and inflammatory. Scand J Gastroenterol 2013;25:706-713.

48. Seshamani S, Kumar R, Dassopoulos T, et al. Augmenting capsule endoscopy diagnosis: a similarity learning approach. Medical image computing and computer-assisted intervention: MICCAI International Conference on Medical Image Computing and Computer-Assisted Intervention 2010;13:454-462.

49. Klang E, Barash Y, Margalit RY et al. Deep learning algorithms for automated detection of Crohn's disease ulcers by video capsule endoscopy. Gastrointest Endosc 2020;91:606-613.e2.

50. Freitas M, Arieira C, Carvalho PB, et al. Simplify to improve in capsule endoscopy - TOP 100 is a swift and reliable evaluation tool for the small bowel inflammatory activity in Crohn's disease. Scand J Gastroenterol 2020;55:408-413.

51. Barash Y, Azaria L, Soffer S, et al. Ulcer severity grading in video capsule images of patients with Crohn's disease: an ordinal neural network solution. Gastrointest Endosc 2020.

52. Rubio-Tapia A, Ludvigsson JF, Branter TK, et al. The prevalence of celiac disease in the United States. Am J Gastroenterol 2012;107:1538-1544.

53. Green PHR. The role of endoscopy in the diagnosis of celiac disease. Gastroenterol Hepatol 2014;10:522-524.

54. Ciaccio EJ, Tennyson CA, Bhagat G, et al. Classification of videocapsule endoscopy image patterns: comparative analysis between patients with celiac disease and normal individuals. Biomed Eng Online 2010;9:44.

55. Zhou T, Han G, Li BN, et al. Quantitative analysis of patients with celiac disease by video capsule endoscopy: A deep learning method. Comput Biol Med 2017;85:1-6.

56. Koh JEW, Hagiwara Y, Oh SL, et al. Automated diagnosis of celiac disease using DWT and nonlinear features with video capsule endoscopy images. Future Gener Comp Sy 2019;90:86-93.

57. Wang X, Qian H, Ciaccio EJ, et al. Celiac disease diagnosis from videocapsule endoscopy images with residual learning and deep feature extraction. Comput Methods Programs Biomed 2020; 187:105236.

58. Seguí S, Drozdzal M, Vilariño F, et al. Categorization and segmentation of intestinal content frames for wireless capsule endoscopy IEEE Eng Med Biol Soc 2012;16:1341-1352.

59. M Ionescu, A Tudor, OA Vatamanu, et al. Detection of lumen and intestinal juices in wireless capsule endoscopy. Comput Sci Series 2013;11:61-65

60. Wang C, Luo Z, Liu X, et al. Organic Boundary Location Based on Color-Texture of Visual Perception in Wireless Capsule Endoscopy Video. J Healthc Eng 2018:1-11.

61. Fenwick A. The global burden of neglected tropical diseases. Public Health 2012;126:233-236.

62. Wu X, Chen H, Gan T, et al. Automatic hookworm detection in wireless capsule endoscopy images. IEEE Trans Med Imaging 2016;35:1741-1752.

63. He JY, Wu X, Jiang YG, et al. Hookworm detection in wireless capsule endoscopy images with deep learning. IEEE Signal Processing Society 2018;27:2379-2392.

64. El Hajjar A, Rey JF. Artificial intelligence in gastrointestinal endoscopy: general overview. Chin Med J 2020;133:326-334. 